\title{
Formulation and Evaluation of Mucoadhesive Clotrimazole Vaginal Tablet Using Liquisolid Technology
}

\section{Dr. Rao Monica*, Zope Abhishek}

Department of Pharmaceutics, AISSMS College of Pharmacy, Kennedy Road, Near RTO, Pune-411001

\begin{abstract}
Liquisolid technology is very effective technique for improving the solubility and dissolution properties of poorly water soluble drug formulations like Clotrimazole. Clotrimazole is a BCS Class II, antifungal drug used for treatment for Vaginal Candidiasis. In this liquisolid technique the drug soluble in non volatile solvents and then it converted into free flowing, non adherent powder, which can be compressed into tablet. Here N-methyle-2-pyrrolidone and propylene glycol is used in the ratio of 1:1 as a solvent. Neusilin US2 and Aerosil 200 used as Coating and Carrier material respectively. For mucoadhesion on vaginal wall Sodium carboxymethyle cellulose used as a mucoadhesive agent. Mucoadhesive tablets were prepared using direct compression technique. Magnesium Stearate used as a glidant. Mucoadhesive liquisolid tablets were evaluated as precompression evalutions and post compression evaluations. Future tablets were evaluated as In vitro and Ex vivo evaluations. The optimized batch showed that In vitro release in simulated vaginal fluid pH 4.5 in 6 hr was $99 \%$. Ex vivo diffusion studies of optimized batch showed $80 \%$ of drug diffusion in $6 \mathrm{hr}$. Mucoadhesive strength showed high mucoadhesion of optimized batch that is 36 gm. From this study it was concluded that liquisolid technology is an effective technique to improve solubility and dissolution properties of poorly water soluble drug formulations like Clotrimazole.
\end{abstract}

Keywords: Liquisolid Tablets, Clotrimazole, Non volatile solvents

Article Info: Received 04 July 2019; $\quad$ Review Completed 20 August 2019; Accepted 23 August 2019; Available online 30 Aug 2019

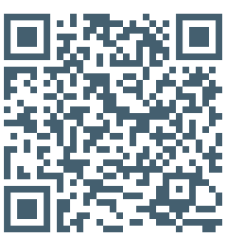

Cite this article as: Rao M, Zope A, Formulation and Evaluation of Mucoadhesive Clotrimazole Vaginal Tablet Using Liquisolid Technology, Journal of Drug Delivery and Therapeutics. 2019; 9(4-A):477-475 http://dx.doi.org/10.22270/jddt.v9i4-A.3444

*Address for Correspondence:

Dr. Rao Monica, Department of Pharmaceutics, AISSMS College of Pharmacy, Kennedy Road, Near RT0, Pune-411001

\section{INTRODUCTION}

Vaginal candidiasis is a fungal infection which is also called as candida vaginitis. It develops in mucosa that usually causes a watery, white, cottage cheese-like vaginal discharge [1]. Many conventional formulations are prepared for treatment of vaginal candidiasis like oral and vaginal tablets. Vaginal drug delivery has many advantages as compared to oral drug delivery like bypassing the first pass metabolism and local drug delivery. For many years imidazole derivatives have been used as drugs of choice for treating this infection. Clotrimazole (CTZ) is BCS class II drug which has prominent antifungal action. It works to kill individual Candida or fungal cells by altering the permeability of the fungal cell wall. It binds to phospholipids in the cell membrane and inhibits the biosynthesis of ergosterol and other sterols required for cell membrane production. This leads to the cell's death via loss of intracellular elements [2]. CTZ is available in various formulations like tablets, creams, gels for local treatment. However, a major problem with these formulations is low residence time [3].

Liquisolid technology is used to enhance solubility and dissolution of drug. In liquisolid technique the drug is

ISSN: 2250-1177

[477] dissolved in a suitable solvent and the liquid medication is loaded on solid carrier and coating material. A flowable, compressible powder is obtained by addition of suitable excipients like disintegrants, glidants and lubricants. Liquisolid compacts are prepared by direct compression or slugging method. It is cost effective technique and easy for industrial production [4]. Generally water insoluble or poorly water soluble drugs are dissolved in non volatile organic solvents like propylene glycol (PG), polyethylene glycols 400 (PEG 400), N-methyle-2-Pyrrilidone (NMP) etc. These solvents are then loaded on various ratios of carrier and coating materials till a flowable, compressible powder is obtained.

The aim of this study was to enhance solubility and dissolution rate of CTZ by liquisolid technique and formulation of mucoadhesive CTZ vaginal tablet using suitable mucoadhesive agent. A $3^{2}$ factorial design was employed for formulation designs of batches. Carrier/coating material and mucoadhesive agent were the two independent factors selected and percent drug diffusion and mucoadhesive strength were selected as responses. Liquid Load Factor ( $\mathrm{Lf}_{\mathrm{f}}$ ) was calculated for various carrier/coating ratios for selection of suitable CODEN (USA): JDDTAO 
carrier/coating ratios and materials. Further liquisolid tablets were evaluated for precompression and post compression micromeritic properties, ex vivo studies and stability studies.

\section{MATERIALS AND METHODS}

\section{Materials:}

Clotrimazole was a kind gift of Amoli organics, Vapi, India, Neusilin US2 also was a kind gift of Gangwal Chemicals, Bhiwandi India, Aerosil 200 was purchased from Analab Fine Chemicals, Mumbai, India, Propylene glycol, Polyethylene glycol 400, N-methyle-2-Pyrrilidone, Tween 80, Tween 20 are purchased from Loba Chemicals, Mumbai, India. All chemical used in this study were the analytical grade.

\section{Methods}

\section{Drug-excipient compatibility studies}

The IR spectrum of CTZ was recorded using FTIR spectrophotometer. Sample preparation involved triturating the mixture of sample \& potassium bromide $(\mathrm{KBr})$ in the ratio 1:50. The resultant triturate was placed in the sample cup and was scanned over a frequency ranging 4000-400 $\mathrm{cm}^{-1}$. The mixtures of Neusilin US2, Aerosil 200 and sodium CMC with CTZ were analyzed for IR Spectra.

\section{UV-visible spectroscopy method}

A UV spectrum of CTZ was determined using methanol AR Grade as solvent. $\lambda_{\max }$ was determined along with calibration curve using concentration range $10-50 \mu \mathrm{g} / \mathrm{ml}$ which obeys Beers Lamberts law [5].

\section{Selection of non volatile solvent}

Solubility of drug in various solvents like propylene glycol, polyethylene glycol 400, N-methyl-2-pyrrolidone, Tween 80 Tween 20 was determined. An excess amount of CTZ was added to $10 \mathrm{ml}$ of solvents in the conical flasks to prepare saturated solutions. These saturated solutions were subjected to constant shaking on incubator shaker for $48 \mathrm{~h}$ at room temperature $30^{\circ} \mathrm{C}$. After shaking, the saturated solutions were centrifuged at $3000 \mathrm{rpm}$ and supernatant was filtered through $0.45 \mu$ cellulose acetate filter. Amount of drug in filtrate was measured using UV-VIS spectrophotometer at $227 \mathrm{~nm}$ after diluting with methanol [6].

\section{Determination of Flowable liquid load factor for carrier/coating ratios [6] [7]}

The experiment was designed to measure the flowable liquid retention potential ( $\Phi$-value) for Neusilin US2, microcrystalline cellulose (MCC), lactose, and Aerosil 200. To $10 \mathrm{~g}$ of carrier/coating material, increasing amounts $(0.01$ $\mathrm{ml}$ ) of nonvolatile solvent were added and mixed well by triturating in glass mortar and angle of repose for powder was determined. The corresponding $\Phi$-value was calculated from the following equation:

$$
\frac{\text { Weight of liquid }}{\text { Weight of carrier or coat }}=\Phi-\text { value }
$$

The liquid load factor ( $\mathrm{Lf}_{\mathrm{f}}$ ) is calculated from the weight the liquid medication (W) and carrier powder (Q) in the system by following equation

$\mathrm{L}_{\mathrm{f}}=\frac{W}{Q} \quad$-------Equation no.
The excipient ratio $(R)$ is the ratio of the weights of the carrier (Q) and the coating (q) material present in the formulation

$\mathrm{R}=\frac{Q}{q} \quad$------Equation no. (3)

The liquid load factor (Lf) for acceptable flowability was calculated based on the $\Phi$-value of carrier and coating material using following equation

$\mathrm{Lf}=\Phi_{\mathrm{CA}}+\Phi_{\mathrm{CO}}(1 / \mathrm{R}) \quad$------Equation no. (4)

Where, $\Phi_{\mathrm{CA}}=\Phi$ value for carrier material

$\Phi_{\mathrm{C} 0}=\Phi$ value for coating material

$\mathrm{R}=$ Ratio of weight of carrier to coating material

\section{Determination of amount of carrier $(Q)$ and coating (q) material}

Quantity of carrier $(Q)$ can be determined from using equation $\left(\mathrm{L}_{\mathrm{f}}=W / Q\right)$

$\mathrm{Q}=\mathrm{W} / \mathrm{Lf}_{\mathrm{f}} \quad$------ Equation no. (5)

Then using equation $(R=Q / q)$, quantity of coating material can be calculated:

$\mathrm{q}=Q / R \quad$-------Equation no. (6)

\section{Preparation of Liquisolid tablets of Clotrimazole:}

Liquisolid compacts were prepared in three step process. In first step, liquid medication was prepared by dissolving accurately weighed CTZ in the specified amount of solvent. In the second step liquid medication obtained in first step was adsorbed on calculated amount of carrier material by trituration using mortar and pestle. To the obtained blend of liquid medication and carrier material, defined quantity of coating material (Aerosil 200) was added and mixed continuously to obtain dry powder admixture. The final powder blend was mixed with sodium CMC as mucoadhesive agent, magnesium stearate as glidant, talc as lubricant in mortar and pestle. The tablets were prepared using direct compression technique on tablet compression machine (Mini Press-II MT) using $10 \mathrm{~mm}$ punch.

\section{Statistical design:}

A $3^{2}$ full factorial design was used to formulate the tablets. The design consisted of two factors at three levels and experimental trials were performed at all possible nine combinations. Carrier/coating material and mucoadhesive agent were the two independent factors selected and percent drug diffusion and mucoadhesive strength were selected as responses (Table 3 ).

\section{Pre compression evaluation parameters ${ }^{[8]}[9]$}

The various powder flow properties were evaluated like Angle of repose, Bulk density, Tapped density, Hausner's ratio and Carr's index.

i. Angle of repose: The angle of repose for the powder blend was determined by fixed funnel method. Angle of repose was calculated using equation:

Tan $\theta=h / r \quad$-------Equation no. (7)

Where, $\quad \mathrm{h}=$ height of powder heap in $\mathrm{cm}$

$\mathrm{r}=$ radius of powder heap in $\mathrm{cm}$

ii. Tapped bulk density (TBD): About 5 grams of powder sample was poured gently through a glass funnel into a $10 \mathrm{ml}$ graduated cylinder. The cylinder was tapped from height of 2 inches until a constant volume was obtained. Volume 
occupied by the sample after 100 tapping were recorded and tapped density was calculated as follows:

Tapped density $=\frac{\text { Mass }}{\text { Tapped volume }}$--------Equation no. (8)

iii. Bulk density (BD): Bulk density of the powder was determined by pouring gently $5 \mathrm{gms}$ of sample through a glass funnel into a $10 \mathrm{ml}$ graduated cylinder. The volume occupied by the sample was recorded. The bulk density was calculated as follows:

$$
\text { Bulk density }=\frac{\text { Mass }}{\text { Bulk Volume }} \quad \text {-------Equation no. (9) }
$$

iv. Carr's Compressibility Index (CI): The compressibility index of the powder blend was determined using Carr's compressibility index:

$C I=\frac{\text { Tapped Bulk Density-Bulk Density }}{\text { Tapped bulk density }} * 100 \quad$-----Equation no.

v. Hausner ratio: Hausner ratio was determined for characterization of flow of powder blend. A Hausner ratio greater than 1.25 is considered to be an indication of poor flowability. Formula used was as follows:

Hausner Ratio= $\frac{\text { Tapped Bulk Density }}{\text { bulk density }} \quad-$-----Equation no.

\section{Post Compression Evaluations}

\section{i. Hardness and thickness}

The resistance of tablets to shipping or breakage under conditions of storage, transportation and handling before usage depends on its hardness. The hardness of tablet of each formulation was measured by Monsanto hardness tester (Nevtex). The hardness was measured in terms of $\mathrm{kg} / \mathrm{cm} 2$. [10] Thickness and diameter of tablets were important for uniformity of tablet size. Thickness and diameter were measured using digital Vernier Caliper (Swastik, Mumbai).

\section{ii. Friability}

Friability is the measure of tablet strength. Roche friabilator (Veego, Mumbai) was used for testing the friability using the following procedure. Ten tablets were weighed accurately and placed in the tumbling apparatus that revolves at 25 rpm dropping the tablets through a distance of six inches with each revolution. After 4 min., the tablets were weighed and the percentage loss in tablet weight was determined. [11]

\section{iii. Uniformity of weight}

Twenty tablets were weighed randomly and average weight was calculated. Not more than two of the individual weights deviate from the average weight by more than the percentage shown in table and none deviates by more than twice that percentage.

\section{iv. Determination of drug content}

Twenty tablets of each batch were randomly selected, weighed and powdered. The quantity of powder equivalent to $25 \mathrm{mg}$ of CTZ was taken and dissolved in $10 \mathrm{ml}$ of methanol and filtered [12]. The absorbance was measured spectrophotometrically at $227 \mathrm{~nm}$ after suitable dilution.

\section{In vitro dissolution studies}

The in vitro dissolution studies were carried out using USP apparatus type II (DA 8000, Labindia) at $50 \mathrm{rpm}$. The dissolution medium was $500 \mathrm{ml}$ of simulated vaginal fluid maintained at $37^{\circ} \mathrm{C} \pm 0.5^{\circ} \mathrm{C}$. Aliquots of $5 \mathrm{ml}$ were withdrawn at $1 \mathrm{~h}$ interval till $6 \mathrm{~h}$. The aliquots were then analyzed by UV spectrophotometer at $227 \mathrm{~nm}$ [13].

ISSN: 2250-1177

\section{Determination of mucoadhesive strength:}

Mucoadhesive strength was evaluated using a Texture Analyzer (CT 3 Texture Analyzer, Brookfield Engineering Labs, Inc., Model Texture Pro CT V1.4 Build 17). Fresh sheep vaginal mucosa was obtained from a local slaughter house and was used within $2 \mathrm{~h}$ of slaughtering. The mucosal membrane was washed with distilled water and then with acetate buffer $\mathrm{pH}$ 4.6, subsequently it was carefully attached to a $10-\mathrm{mm}$ cylindrical probe (TA 3/100probe) using a double-sided adhesive tape. The upper platform was moved downward manually near to the tablet surface and then the mucosa was brought toward the tablet at a constant speed of $1 \mathrm{~mm} / \mathrm{s}$ until a predetermined compressive force of $0.5 \mathrm{~N}$ was applied with holding time of $60 \mathrm{~s}$ and load cell of $1000 \mathrm{gm}$. The probe was then removed with return speed of $1 \mathrm{~mm} / \mathrm{s}$ to a distance of $15 \mathrm{~mm}$ and maximum detachment force $(\mathrm{g})$ was determined for each sample with data rate 15 points/sec. For each new sample, a different mucosa sample was used [2].

\section{Optimization and validation model}

The response from the release data and mucoadhesive force was fed to the Design expert software 11.0 and polynomial equations were generated. Numerical optimization was done using desirability function and predicted formula was prepared and analyzed to test whether the result matches predicted results by DOE.

\section{Ex- vivo diffusion studies}

Ex vivo drug permeation studies of the drug through the sheep vaginal membrane was performed using Franz diffusion cell at $37^{\circ} \mathrm{C} \pm 0.2^{\circ} \mathrm{C}$. Fresh sheep vaginal tissue was mounted between the donor and receptor compartments. The optimized vaginal tablet was placed with the core facing the tissue and the compartments clamped together. Both donor and receptor compartments were filled with $8 \mathrm{ml}$ of simulated vaginal fluid $(\mathrm{pH} 4.5)$ and stirred with magnetic bead at $50 \mathrm{rpm}$. Samples of $1 \mathrm{ml}$ were withdrawn every hour (up to $6 \mathrm{~h}$ ) and analyzed for drug content at $227 \mathrm{~nm}$ using an ultraviolet-visible spectrophotometer [14].

\section{Swelling Index}

Optimized vaginal tablets were weighed individually $(W 1)$ and placed separately in petri dishes containing $4 \mathrm{ml}$ of simulated vaginal fluid $(\mathrm{pH} 4.5)$ solution. At regular intervals $(1,2,3,4,5$ and $6 \mathrm{~h})$, the tablets were removed from the petri dishes and excess surface water was removed carefully using filter paper [15]. The swollen tablets were then reweighed (W2) and swelling index (SI) was calculated using the following formula:

Swelling Index $=(W 2-W 1) / W 1^{*} 100 \quad$----Equation no. $(14)$

\section{Stability studies}

The optimized formulation was subjected to stability studies at $40^{\circ} \mathrm{C} / 75 \%$ Relative Humidity (RH) for 45 days. Samples were withdrawn at 15-days time interval and evaluated for physical properties, drug content and drug dissolution [16].

\section{RESULTS AND DISCUSSION}

\section{Drug-excipient compatibility studies}

This test was carried out to check the interaction of drug and excipients. The FT-IR spectra of CTZ shows the absorption band at $1440 \mathrm{~cm}^{-1}, 1590 \mathrm{~cm}^{-1}, 1674 \mathrm{~cm}^{-1}$ due to C-N stretching, $\mathrm{N}-\mathrm{H}$ bending and $\mathrm{C}=\mathrm{O}$ stretching of primary amide group. It is further noted that out of plane $\mathrm{N}-\mathrm{H}$ wagging, C-N stretching vibrations, N-H bending, free asymmetric and symmetric $\mathrm{N}-\mathrm{H}$ stretching vibrations 
appears at $750 \mathrm{~cm}^{-1}, 1208 \mathrm{~cm}^{-1}$ and $3062 \mathrm{~cm}^{-1}$, respectively. Absorption bands at $455 \mathrm{~cm}^{-1}, 1091 \mathrm{~cm}^{-1}$ are assigned due to out of plane $\mathrm{C}=\mathrm{C}$ bend and in plane $\mathrm{C}-\mathrm{H}$ bend. It can be seen that absorption bands in the range of at 2229-2638 $\mathrm{cm}^{-1}$ are due to methyl $\mathrm{C}-\mathrm{H}$ stretching. By comparing the spectra of CTZ and its physical mixture, it was observed that all the peaks lie in their appropriate range. No changes were observed which indicated there was no interaction between CTZ and excipients.

\section{Selection of non volatile solvent}

Solubility data of drug CTZ was determined in 1:1 ratios of various non-volatile liquid vehicles. CTZ was found be more soluble in NMP:PG liquid than other liquids. CTZ found to have very less solubility in water. The solvent selection for preparation of liquisolid powder is also determined by high solubility of drug in solvent. Hence the NMP:PG was selected as a solvent as the solubility of drug in this solvent is high (Fig. 2). NMP and PG are miscible with water have good solubilizing properties [17][18][19].

\section{Determination of flowable liquid load factor for carrier/coating ratios}

The $\Phi_{\mathrm{CA}}$-value and $\Phi_{\mathrm{Co}}$-value decide the amount of carrier and coating materials required to produce dry, non adherent, free-flowing and readily compatible liquisolid formulations. Hence, determination of the flow properties of powder excipients and liquid/powder admixtures is an important step to produce a successful liquisolid formulation. MCC, lactose, Neusilin US2, and Aerosil 200 were examined as carrier and coating materials for preparing liquisolid tablets. Ratios of MCC/Aerosil, lactose/Aerosil showed high liquid load factors but they exhibited poor flowability. On the other hand Neusilin/Aerosil ratios showed less liquid load factor but the angle of repose indicated good flowability of powder (Table 3).

\section{Preparation and evaluation of liquisolid tablets of CTZ}

A 3 - Level Factorial Design $\left(3^{2}\right)$ was employed for the optimization of liquisolid formulation. The levels of were varied as 5, 12.5, 20 of factor 1 (carrier: coating ratio) and 12 $\mathrm{mg}, 19 \mathrm{mg}, 27 \mathrm{mg}$ of factor 2 (amount of mucoadhesive agent). The data obtained clearly shows that responses are strongly dependent on the independent variables. The experimental batches were optimized using Design Expert Software version 11.0. The 9 batches predicted by the optimization software (Table 5) were analyzed for responses such as \% drug diffusion (\%) (A) and mucoadhesive force (g) (B). Table no. 4 shows liquid load factor and quantities of carrier (Q), coating material (q) and the weight of liquid medication (W).The liquid load factor of different ratios of Neusilin US2 ${ }^{\circledR}$ and Aerosil $200{ }^{\circledR}$ were found to be conducive for good flowability of powder. Their high carrier: coating ratios showed high liquid load factor.

\section{Statistical analysis of $3^{2}$ full factorial design for formulation of liquisolid compacts}

Using Design Expert ${ }^{\circledR}$ Software version 11 (Stat-Ease, Inc., Minneapolis, USA), statistical experimental design for $3^{2}$ factorial design was evaluated. The values of examined responses obtained for all trial formulations were fitted in the $3^{2}$ factorial design to get model equations for responses analyzed. Quantitative effect of independent variables in the obtained equation were mean results obtained by changing one factor from its low to high value keeping another factor constant. Response surface methodology is a widely used approach for the development and optimization of formulation variables. The polynomial equation obtained was visualized with the help of 3D response surface graphs.

\section{i. Ex vivo drug diffusion in $6 \mathrm{~h}$}

The independent factor (A) that is carrier/coating ratio showed positive effect on diffusion of drug through vaginal tissue. As the carrier: coating ratio increases diffusion of drug also increases which may be because of liquid being loaded on carrier and on coating material. The low particle size of the carrier (Neusilin: 60-100 $\mu \mathrm{m}$ ) and coating materials (Aerosil: $100 \mu \mathrm{m}$ ) provides larger surface area for adsorption of the liquid thus enabling uniform, thin film of the liquid on the particle surfaces. Factor B (concentration of mucoadhesive agent) did not have a significant effect on percent diffusion. As per ANOVA the p-value is 0.0014, pvalue less than 0.0500 indicated quadratic model terms were significant. The Model F-value of 105.05 also implied the model was significant. In 3D graph (Fig 3) the highest point indicates that the F6 batch which showed highest carrier: coating ratio and highest amount of mucoadhesive agent that is sodium CMC. So by this batch results there might be high diffusion and high mucoadhesion.

\section{Percent Diffusion=}

$+66.30+14.33 \mathrm{~A}-0.9300 \mathrm{~B}+3.61 \mathrm{AB}+2.18 \mathrm{~A}^{2}-1.12 \mathrm{~B}^{2}$

\section{----Equation no. (1)}

As per the data of ex vivo \% diffusion of CTZ (Table 5), F8 batch showed $80 \%$ diffusion while F6 batch showed $87.59 \%$ diffusion on sheep vaginal tissue in $6 \mathrm{~h}$. F1 batch showed lowest diffusion that is 50\%. F6 batch has high carrier/coating ratio may be because it F6 batch showed more drug diffusion. From the results it can be concluded that there was a direct relationship between the powder excipient ratio $(R)$ and the release of drug from liquisolid tablets, when $R$ value increases, the release rate will also increase. The ex vivo \% drug diffusion graph indicates high $\%$ drug diffusion of F6 batch due to its high Neusilin US2 ${ }^{\circledR} /$ Aerosil $200{ }^{\circledR}$ ratio. High amount of liquid medication adsorbed on this ratio hence more \% drug diffusion may be showed by the results.

\section{ii. Mucoadhesive strength}

The following equation was statistically significant and followed the quadratic model.

\section{Mucoadhesive Strength $=$}

\section{$+18.97-0.5200 \mathrm{~A}+0.6767 \mathrm{~B}+0.8025 \mathrm{AB}-2.10 \mathrm{~A}^{2+14.12 B^{2}}$}

\section{---Equation no. (2)}

The concentration of mucoadhesive agent (B) had an obvious positive effect on mucoadhesive strength. As the amount of mucoadhesive agent increases the mucoadhesion strength also increases. This also indicates that the powder mixture of carrier and coating material did not significantly impact the mucoadhesive strength of the tablets. The equation showed that mucoadhesive agent showed positive effect on mucoadhesion and negative effect on diffusion of drug. As per ANOVA for mucoadhesion response the $p$-value was 0.0026 , p-value less than 0.0500 showed model terms significant. The Model F-value of 71.05 implied the significance of quadratic model. In this 3D graph (Fig. 5) the highest point showed that the batch F6 showed the high quantity of carrier: coating ratio and high quantity of mucoadhesive agent that is sodium CMC.

As shown in (Table 5) the high mucoadhesive agents concentration indicated stronger mucoadhesion on sheep vaginal tissue. Sodium CMC is anionic polymer which forms 
strong hydrogen bonds with mucin hence attachment to the mucosal layer is strong [14]. Additionally the polymer chains of the polymer interpenetrate the mucin lining the mucosal membrane giving better mucoadhesivity.

\section{Characterization of factorial batches}

\section{i. Precompression evaluations}

Liquisolid admixtures for CTZ were prepared according to $3^{2}$ full factorial design taking different Lf values. The physical characteristics of flow properties such as angle of repose, Carr's index and Hausner ratio can help in analysing compressibility and flowability of Liquisolid admixtures. Liquisolid powders with an angle of repose $\left(\theta^{\circ}\right)$ in the range of $25^{\circ}-35^{\circ}$ were considered as powders possessing acceptable flow properties. Moreover, powders having Carr's index (C \%) below 15 were considered to have good flow properties and could be successfully compressed into tablets with uniform weight. Powders with low interparticle friction having Hausners ratio less than or equal to 1.18 , indicated good flow. Adsorption of liquid medication on carrier/coating material can greatly influence angle of repose of liquisolid admixture.

\section{ii. Post compression evaluations}

All liquisolid tablets formulated were subjected to post compression parameter studies as showed in (Table 7). The thickness of tablet was increased by an increase in the weight of the tablet. The hardness of all the tablets was observed in the range of $3-5 \mathrm{~kg} / \mathrm{cm}^{2}$ depending on excipient concentration. Uniform drug content was observed for all these formulations as per the IP specification (90-110\%). The friability of the tablets was within the limit, and slight variation in friability was because of the difference in compression force applied and total weight.

\section{iii. In vitro dissolution studies}

As per dissolution studies data showed in (Fig.6), the carrier/coating ratio has been shown to affect the dissolution rate. The increase in carrier coating ratio showed an increase in drug dissolution rate which might be because of the presence of more amount of Neusilin in those formulations which have liquid medication adsorbed on it. F1 batch showed more than $80 \%$ cumulative drug release. F8 batch showed drug release of about $94 \%$ while F9 batch showed high cumulative drug release upto $97 \%$ in $6 \mathrm{~h}$. F6 batch showed highest cumulative drug release of 99\%. F6 batch has high ratio of Neusilin US2 ${ }^{\circledR}$ and Aerosil $200{ }^{\circledR}$ which thereby has higher liquid load factor. A higher carriercoating ratio indicates presence of larger quantity of the carrier material (Neusilin) than coating material (Aerosil).

\section{iv. Swelling Index (SI) of factorial batches}

Liquisolid tablets were placed in simulated vaginal fluid $\mathrm{pH}$ 4.5. At regular intervals $\left(1,2,3,4,5\right.$ and $6^{\text {th }}$ hour) tablets were removed from the petri dishes. Swollen tablets were reweighed and calculated for SI. The $6^{\text {th }} \mathrm{hr}$ results indicated percent swelling index as showed in (Fig. 7). As concentration of mucoadhesive agent increased the swelling also increased. There was slow and gradual increase in swelling of vaginal tablet as it got in contact with simulated vaginal fluid $\mathrm{pH}$ 4.5. The mucoadhesion is a function of swelling index of the polymer. The swelling polymer forms a matrix with channels through which the drug diffuses uniformly.

\section{Selection and validation of optimized batches}

Selection of optimized formulation of liquisolid tablets was carried out; where the various trials were made to attain the goals like maximization of percent drug diffusion of CTZ in vaginal tissue and maximization of mucoadhesion of tablet. The optimize batch was chosen by numeric optimization using the desirability function. The constraints set for numerical optimization of liquisolid tablet formulation included percent drug diffusion (A) and mucoadhesion (B) Based on these two responses ( $A$ and $b$ ), there were three different optimized batches of liquisolid formulation given by the software and among these three different batches of liquisolid tablet, one batches selected as an optimized batch of liquisolid tablet based on their desirability function. Validation of the optimization methodology by comparing the observed responses with those of the predicted response understood that percent prediction error for both the responses (A and $\mathrm{B}$ ) ranging between $1.13 \%$ and $0.44 \%$ of liquisolid tablet formulation. Thus, the formulation batch giving the maximum percent drug diffusion of formulation and maximum mucoadhesion chosen as the optimized batch.

Design expert software gave 3 batches with response results. Then results were compared to actual experimental results value and \% predicated error is calculated. The statistically optimized formulation of CTZ Liquisolid Compacts (01) fulfilled all the physicochemical criteria. The relative errors (\%) between the predicted and experimental values for each response were calculated and the values found to be within $5 \%$. The experimental values were in agreement with the predicted values confirming the predictability and validity of the model. Based on the results obtained formula for optimized liquisolid compacts following formulation variables were considered as optimized and formula for optimized batch is given in (Table 5).

\section{Stability studies}

The optimized formulation (F-6) was subjected to stability studies at $40^{\circ} \mathrm{C} / 75 \% \mathrm{RH}$ for 45 days. Samples were withdrawn at 15-days of time intervals and evaluated for physical properties, drug content and drug dissolution. Results showed that on $45^{\text {th }}$ day $98.65 \% \pm 2.18$ drug content available in formulation and hence this change did not show any significant changes during stability studies. And also this study showed no change in drug dissolution.

\section{CONCLUSION}

The complete summary of present work concludes that the Liquisolid technique is good method for improving dissolution of poor water soluble drug. The results obtained from $3^{2}$ factocrial design in this study suggest that Neusilin US2: Aerosil 200 ratio (20) and Sodium CMC (27 mg) is the best formulation. The optimize batch showed acceptable values of precompression and post compression parameters. The liquisolid compacts of optimized formula were successfully compressed without any difficulties. The prepared compacts showed improved dissolution.

\section{ACKNOWLEDGEMENT}

Authors are thankful to A.I.S.S.M.S. College of Pharmacy, Pune, for providing the required facilities for the research work.

\section{REFERENCES}

1. Mendling W, Brasch J, Guideline vulvovaginal candidosis (2010) of the German Society for Gynecology and Obstetrics, the Working Group for Infections and Infectimmunology in Gynecology and Obstetrics, the German Society of Dermatology, the Board of German Dermatologists and the German Speaking Mycological Society. Mycoses 55, 2012:3;1-13.

2. Bedekar S, Dr. Madgulkar AR, Formulation Development of Vaginal Drug Delivery for Antifungal and Antiretroviral Drugs, 2016; 13-15. 
3. Baloglu E, Senyigit ZA, Karavana SY, Bernkop-Schnürch A, Strategies to Prolong the Intravaginal Residence Time of Drug Delivery Systems. Journal of Pharmacy and Pharmaceutical sciences, 2009:12(3): 312-336.

4. Vyas PR and Patel KJ. Enhancement of Solubility of Itraconazole Using Novel Liquisolid Technique, An International Journal of Pharmaceutical Sciences, 2015:6(2); 269-286.

5. Mahmood S, Ahmad Z, Aslam M, Naeem F, Hussain A, Naresh Kumar, Method development and validation for estimation and evaluation of Clotriamzole (an-Antifungal Drug) in Tablet Preparation by UV-VIS Spectroscopy, International Journal of Pharmaceutical Sciences Review and Research 2015;32(2):5558.

6. Kumar DS, C.Aparna, Dr. Srinivas P, Immediate And Mucoadhesive Sustained Release Compacts Of Itraconazole Using Liquisolid Technology, International Journal of Pharmacy and technology, 2015; 7(3):9513-9533.

7. Kala NP, Shastri DH, Shelat PK, Design and Characterization of Buccoadhesive Liquisolid System of an Antihypertensive Drug, Hindawi Publishing Corporation Journal of Drug Delivery, 2015: $1-9$.

8.https://www.usp.org/sites/default/files/usp/document/harmoni zation/gen chapter/g05_pf_30_6_2004.pdf (accessed on 4/04/2019)

9. Begum MY, Avanthi J, Shwetha A, Madhuri T, Sudhakar M and Naveen D, Formulation And Evaluation of Sustained Release Floating Tablets of Loratadine. International Journal of Pharmaceutical Sciences and Research, 2014;5(10): 4375-4385.

10. Charyulu NR, Bera D, Sakhia D, Manavadaria KZ, Shetty NG, Formulation and evaluation of bilayer floating tablets of
Diltiazem hydrochloride for bimodal release. International Journal of Research in Pharmaceutical Sciences. 2012 3(2), 301306.

11. Mogal SA, et al. Solid dispersion technique for improving solubility of some poorly soluble drugs. Der Pharmacia Lettre. 2012; 4(5): 1574-1586.

12. https://gpatindia.com/wpcontent/uploads/2010/02/Pharmacopoeial-Tests-forDifferent-dosage-forms.pdf (accessed on 4/04/2019)

13. Ganapuram BR, et al. Development, evaluation and characterization of surface solid dispersion for solubility and dispersion enhancement of irbesartan. Journal of Pharmacy Research, 2013; 472-477.

14. Nipun TS and Islam SA, SEDDS of gliclazide: Preparation and characterization by in-vitro, ex-vivo and in-vivo techniques, Saudi Pharmaceutical Journal, 2014:22(4); 343-348.

15. Shaikh FI, Dr.Patel Vb, Solubility Enhancement and Dissolution Method Development of Some Poorly Soluble Drugs, 2018; 207249.

16.https://www.ich.org/fileadmin/Public_Web_Site/ICH_Products/ Guidelines/Quality/Q1F/Stability_Guideline_WHO_2018.pdf (Accessed on 30/07/2019)

17. Sullivan CJ, Kuenz A and Vorlop KD, Propanediols. Ullmann's Encyclopedia of Industrial Chemistry, 2018;1-15.

18. https://pubchem.ncbi.nlm.nih.gov/compound/Propyleneglycol (Accessed on 30/07/19)

19. https://pubchem.ncbi.nlm.nih.gov/compound/13387\#section =Names-and-Identifiers (Accessed on 30/07/19)

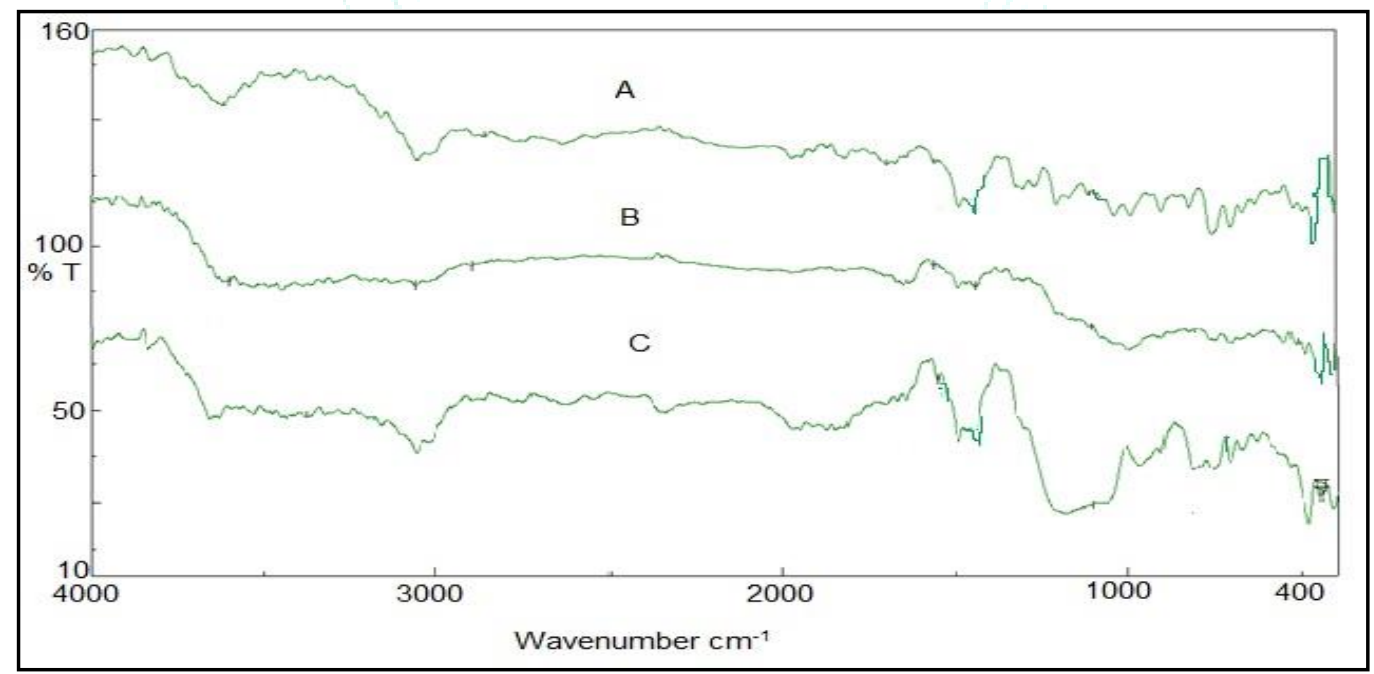

Fig 1. FTIR spectra (after 30 days) for drug-excipient compatibility studies.

Drug and Sodium CMC (A), drug and Neusilin (B), drug and Aerosil 200 (C)

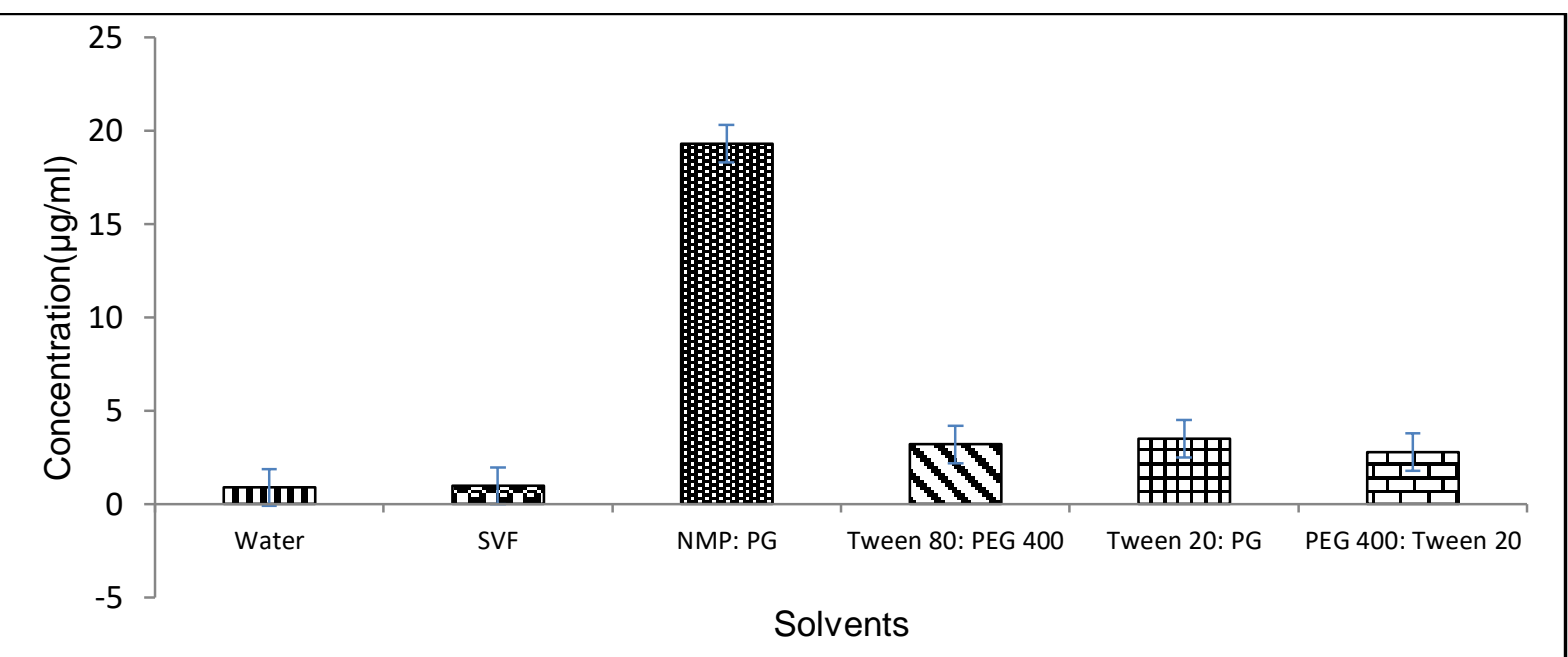

Fig 2: Solubility of Clotrimazole in different solvents 


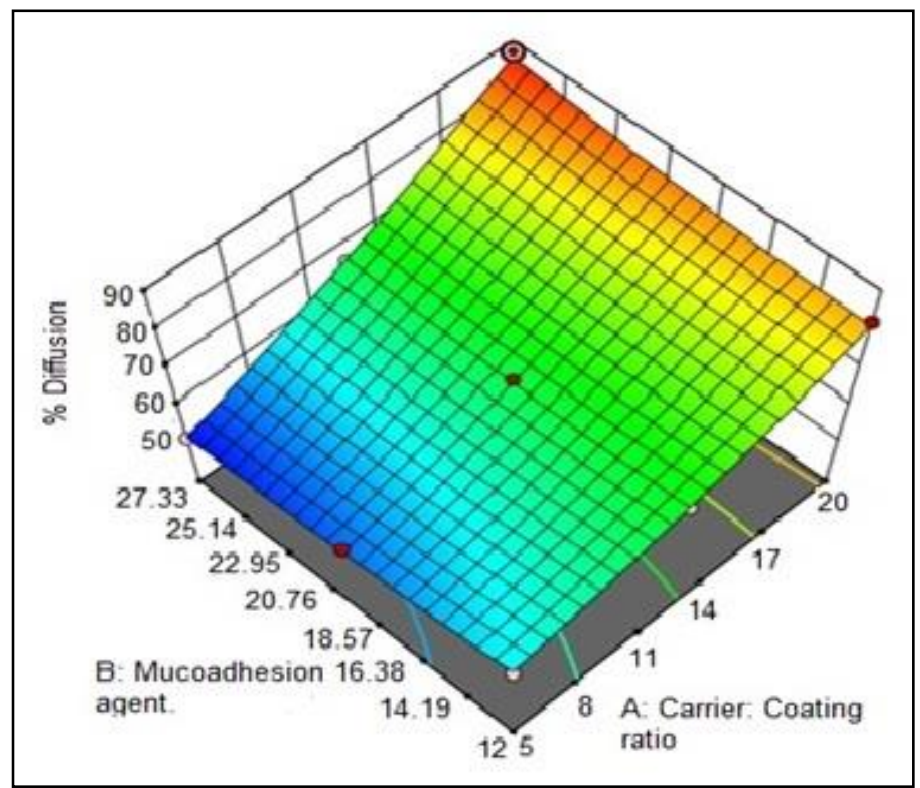

Fig 3: Response surface plot for $\%$ diffusion of Clotrimazole

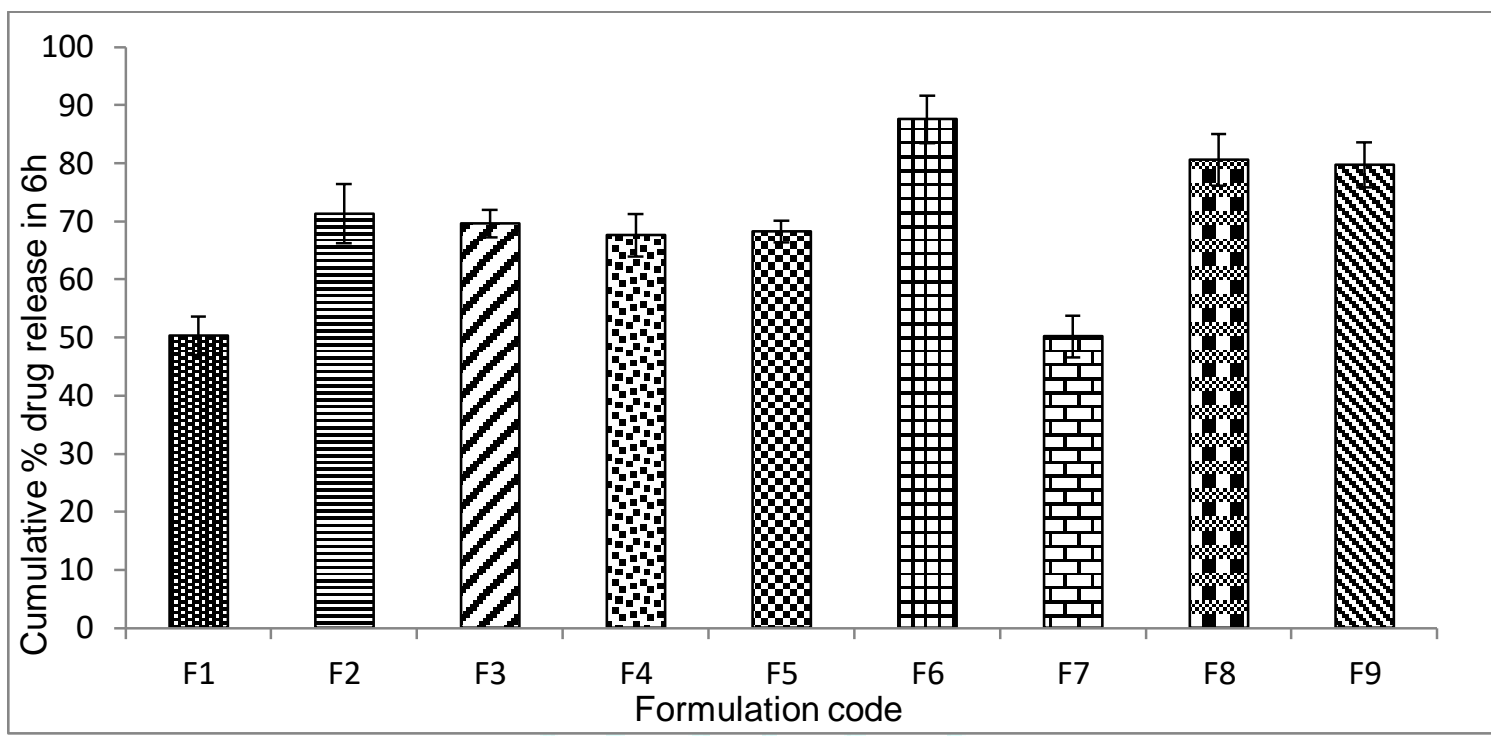

Fig.4 Ex vivo \% drug diffusion of CTZ in $6 \mathrm{~h}$

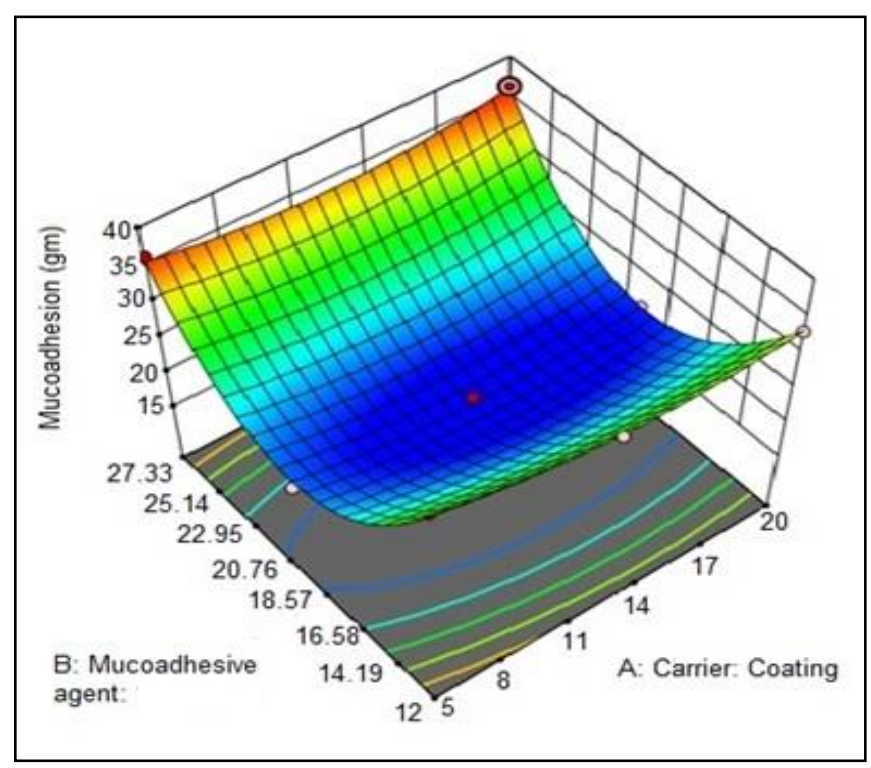

Fig 5: Response surface plot of mucoadhesion of Clotrimazole 


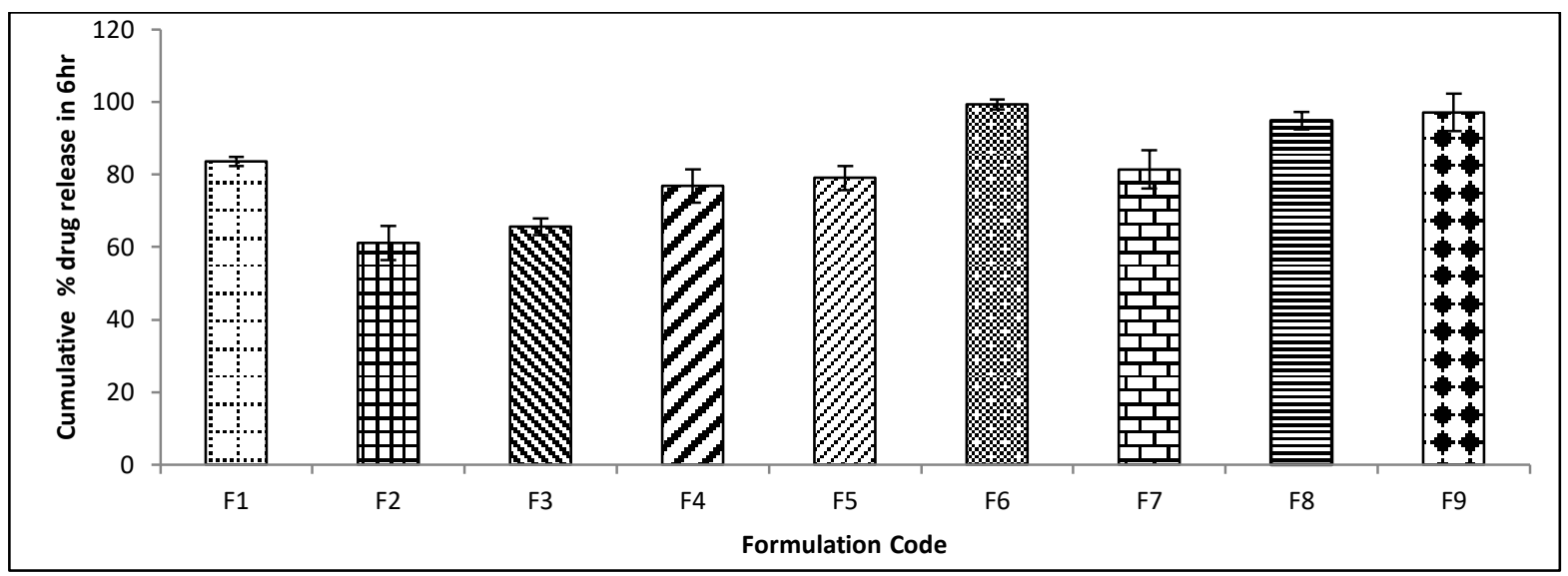

Fig 6: In vitro drug release of CTZ in $6 \mathrm{~h}$

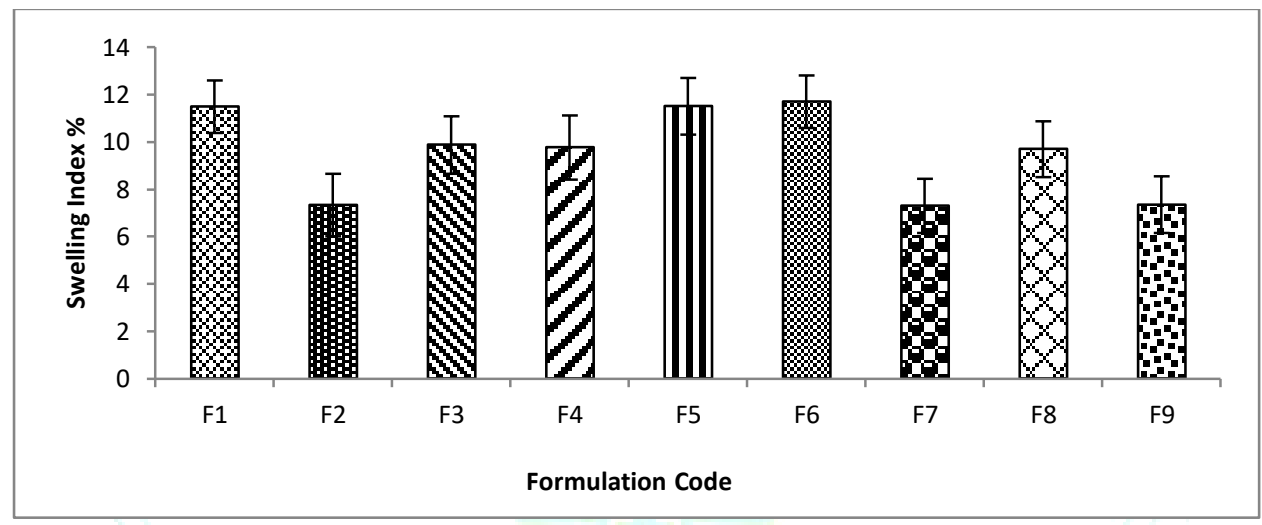

Fig 7. Swelling index of batches F1-F9

Table 1: Actual \& coded levels of the factors

\begin{tabular}{|c|c|c|c|c|c|c|}
\hline \multirow{2}{*}{ Factor } & \multicolumn{3}{|c|}{ Actual values } & \multicolumn{3}{c|}{ Coded values } \\
\cline { 2 - 7 } & low & Mid & High & Low & Mid & High \\
\hline Factor A Excipient ratio & 5 & 12.5 & 20 & -1 & 0 & 1 \\
\hline Factor B Sodium CMC & $12 \mathrm{mg}$ & $18 \mathrm{mg}$ & $27 \mathrm{mg}$ & -1 & 0 & 1 \\
\hline
\end{tabular}

Table 2: Solubility data of Clotrimazole in different solvent Data expressed as mean \pm SD $(n=3)$

\begin{tabular}{|l|l|l|}
\hline Sr.no & \multicolumn{1}{|c|}{ Solvents } & Soluble concentration(mg/ml) \\
\hline 1 & Water & $0.00387 \pm 0.00257$ \\
\hline 2 & Simulated Vaginal Fluid $\mathrm{pH} 4.5$ & $0.1719 \pm 0.0644$ \\
\hline 3 & NMP: PG & $19.96 \pm 0.6$ \\
\hline 4 & Tween 80: PEG 400 & $2.2 \pm 1.7$ \\
\hline 5 & Tween 20: PG & $1.83 \pm 0.51$ \\
\hline 6 & PEG 400: Tween 20 & $2.1 \pm 1.1$ \\
\hline
\end{tabular}

Table 3: Flowable Liquid Retention Potential ( $\Phi$ - value)

\begin{tabular}{|c|c|c|c|c|c|}
\hline $\begin{array}{l}\text { Carrier/Coating } \\
\text { materials }\end{array}$ & Ratios & $\begin{array}{c}\text { Angle of } \\
\text { repose }\left(\theta^{0}\right)\end{array}$ & $\begin{array}{c}\text { Liquid retention } \\
\text { Potential of Carrier } \\
\left(\Phi_{\mathrm{CA}}-\text { value }\right)\end{array}$ & $\begin{array}{c}\text { Liquid retention } \\
\text { potential of Coating } \\
\text { material }\left(\Phi_{\mathrm{Co}}-\text { value) }\right.\end{array}$ & $\begin{array}{c}\text { Liquid Load } \\
\left.\text { Factor ( } L_{f}\right)\end{array}$ \\
\hline \multirow[t]{4}{*}{ MCC/Aerosil } & 5 & 45.23 & 0.22 & 4.23 & 0.8901 \\
\hline & 10 & 44.24 & 0.29 & 5.11 & 0.5400 \\
\hline & 15 & 40.11 & 0.35 & 5.88 & 0.4153 \\
\hline & 20 & 39.96 & 0.41 & 6.01 & 0.3210 \\
\hline \multirow[t]{4}{*}{ Lactose/Aerosil } & 5 & 32.21 & 0.21 & 4.11 & 0.8640 \\
\hline & 10 & 35.62 & 0.29 & 4.66 & 0.4950 \\
\hline & 15 & 40.66 & 0.35 & 5.12 & 0.3646 \\
\hline & 20 & 40.74 & 0.48 & 5.33 & 0.2905 \\
\hline \multirow[t]{4}{*}{ Neusilin/Aerosil } & 5 & 29.12 & 0.41 & 1.75 & 0.4320 \\
\hline & 10 & 27.32 & 0.34 & 4.09 & 0.4430 \\
\hline & 15 & 26.11 & 0.44 & 6.55 & 0.4660 \\
\hline & 20 & 29.33 & 0.75 & 8.88 & 0.4815 \\
\hline
\end{tabular}


Table 4: Formulation design of factorial batches

\begin{tabular}{|c|c|c|c|c|c|c|c|c|}
\hline Batches & $\begin{array}{l}\text { Drug } \\
\text { (mg) }\end{array}$ & $\begin{array}{l}\text { Liquid Load } \\
\text { Factor (Lf) }\end{array}$ & $\begin{array}{l}\text { Amount of } \\
\text { Carrier (Q) } \\
\text { (mg) }\end{array}$ & $\begin{array}{l}\text { Amount of } \\
\text { Coating material } \\
\text { (q) (mg) }\end{array}$ & $\begin{array}{l}\text { Weight of } \\
\text { Liquid (W) } \\
\text { (mg) }\end{array}$ & $\begin{array}{l}\text { Magnesium } \\
\text { Stearate (mg) }\end{array}$ & $\begin{array}{l}\text { Talc } \\
\text { (mg) }\end{array}$ & $\begin{array}{l}\text { Total } \\
\text { weight } \\
\text { (mg) }\end{array}$ \\
\hline F1 & 25 & 0.2655 & 83.48 & 16.69 & 131.57 & 10 & 5 & 271.74 \\
\hline F2 & 25 & 0.3449 & 231.96 & 18.55 & 131.57 & 10 & 5 & 422.08 \\
\hline F3 & 25 & 0.2655 & 83.48 & 16.69 & 131.57 & 10 & 5 & 271.74 \\
\hline F4 & 25 & 0.3449 & 231.96 & 18.55 & 131.57 & 10 & 5 & 422.08 \\
\hline F5 & 25 & 0.3449 & 231.96 & 18.55 & 131.57 & 10 & 5 & 422.08 \\
\hline F6 & 25 & 0.5672 & 381.47 & 19.07 & 131.57 & 10 & 5 & 572.11 \\
\hline F7 & 25 & 0.2655 & 83.48 & 19.69 & 131.57 & 10 & 5 & 271.74 \\
\hline F8 & 25 & 0.5672 & 381.47 & 19.07 & 131.57 & 10 & 5 & 572.11 \\
\hline F9 & 25 & 0.5672 & 381.47 & 19.07 & 131.57 & & 10 & 5 \\
\hline
\end{tabular}

Table 5: $3^{2}$ Statistical design for formulation of liquisolid compacts Data expressed as mean \pm SD $(n=3)$

\begin{tabular}{|c|c|c|c|c|}
\hline Batches & $\begin{array}{c}\text { Factor 1 } \\
\text { A:Carrier:coa } \\
\text { ting ratio }\end{array}$ & $\begin{array}{c}\text { Factor 2 } \\
\text { agent. Na-CMC(mg) }\end{array}$ & $\begin{array}{c}\text { Response 1 } \\
\text { \% Diffusion } \\
\text { (\%) }\end{array}$ & $\begin{array}{c}\text { Rucoadhesion } \\
\text { (gm) }\end{array}$ \\
\hline F1 & 5 & 27 & $50.3 \pm 3.33$ & $36.23 \pm 2.9$ \\
\hline F2 & 12.5 & 12 & $71.27 \pm 5.1$ & $32.15 \pm 3.2$ \\
\hline F3 & 5 & 19 & $69.61 \pm 2.3$ & $20.56 \pm 4.4$ \\
\hline F4 & 12.5 & 19 & $67.06 \pm 3.6$ & $20.03 \pm 5.5$ \\
\hline F5 & 12.5 & 27 & $68.24 \pm 1.9$ & $32.96 \pm 2.3$ \\
\hline F6 & 20 & 27 & $87.59 \pm 4.1$ & $36.3 \pm 3.7$ \\
\hline F7 & 5 & 12 & $50.20 \pm 3.6$ & $36.21 \pm 2.9$ \\
\hline F8 & 20 & 19 & $80.58 \pm 4.5$ & $20.51 \pm 5.5$ \\
\hline F9 & 20 & 12 & $79.71 \pm 3.9$ & $33.07 \pm 4.5$ \\
\hline
\end{tabular}

Table 6: Precompression Evaluation liquisoild powder of factorial batches Data expressed at $\operatorname{Mean} \pm \operatorname{SD}(n=3)$

\begin{tabular}{|c|c|c|c|c|c|}
\hline Batches & $\begin{array}{l}\text { Bulk Density } \\
\text { (gm/ml) }\end{array}$ & $\begin{array}{l}\text { Tapped Density } \\
\mathbf{( g m / m l )}\end{array}$ & $\begin{array}{l}\text { Hausners } \\
\text { Ratio }\end{array}$ & $\begin{array}{l}\text { Carrs Index } \\
\mathbf{( \% )}\end{array}$ & $\begin{array}{l}\text { Angle of Repose } \\
\left(\boldsymbol{\theta}^{\circ}\right)\end{array}$ \\
\hline F1 & $0.21 \pm 0.1$ & $0.23 \pm 0.13$ & $1.09 \pm 0.68$ & $8.70 \pm 4.5$ & $33 \pm 3.52$ \\
\hline F2 & $0.24 \pm 0.57$ & $0.26 \pm 0.15$ & $1.08 \pm 0.2$ & $7.59 \pm 3.5$ & $30.12 \pm 2.41$ \\
\hline F3 & $0.26 \pm 1.57$ & $0.28 \pm 0.16$ & $1.07 \pm 0.22$ & $6.97 \pm 5.10$ & $27.3 \pm 3.54$ \\
\hline F4 & $0.21 \pm 0.1$ & $0.23 \pm 0.15$ & $1.06 \pm 0.89$ & $7.07 \pm 4.63$ & $28.25 \pm 2.66$ \\
\hline F5 & $0.25 \pm 0.12$ & $0.26 \pm 0.12$ & $1.06 \pm 0.65$ & $6.31 \pm 2.63$ & $30.26 \pm 3.12$ \\
\hline F6 & $0.21 \pm 0.13$ & $0.22 \pm 0.16$ & $1.09 \pm 0.66$ & $8.70 \pm 4.45$ & $26.14 \pm 5.5$ \\
\hline F7 & $0.23 \pm 0.14$ & $0.25 \pm 0.15$ & $1.08 \pm 0.96$ & $7.89 \pm 3.89$ & $27.17 \pm 5.12$ \\
\hline F8 & $0.25 \pm 0.16$ & $0.27 \pm 0.16$ & $1.07 \pm 0.85$ & $7.31 \pm 4.78$ & $30.17 \pm 3.33$ \\
\hline F9 & $0.26 \pm 0.13$ & $0.28 \pm 0.18$ & $1.05 \pm 0.64$ & $5.91 \pm 2.12$ & $26.56 \pm 5.23$ \\
\hline
\end{tabular}

Table 7: Post Compression Study of Factorial Batches Data expressed at Mean \pm SD $(n=3)$

\begin{tabular}{|c|c|c|c|c|c|}
\hline Batches & $\begin{array}{l}\text { Hardness } \\
\left(\mathbf{K g} / \mathbf{c m}^{2}\right)\end{array}$ & Friability (\%) & Thickness (mm) & Weight Variation & Drug Content (\%) \\
\hline F1 & $4.33 \pm 1.22$ & $0.5882 \pm 1.23$ & $4.19 \pm 1.36$ & $351.07 \pm 0.607$ & $97.69 \pm 1.12$ \\
\hline F2 & $4.6 \pm 1.54$ & $0.5376 \pm 2.33$ & $5.57 \pm 1.22$ & $434.08 \pm 0.756$ & $96.66 \pm 2.12$ \\
\hline F3 & $3.86 \pm 2.56$ & $0.4040 \pm 3.45$ & $4.0 \pm 1.45$ & $343.40 \pm 0.590$ & $97.58 \pm 2.41$ \\
\hline F4 & $4.46 \pm 1.52$ & $0.3076 \pm 2.11$ & $5.47 \pm 1.98$ & $441.74 \pm 0.751$ & $95.54 \pm 3.66$ \\
\hline F5 & $3.73 \pm 2.23$ & $0.3267 \pm 4.23$ & $5.53 \pm 2.12$ & $449.41 \pm 1.97$ & $97.79 \pm 2.41$ \\
\hline F6 & $4.78 \pm 1.29$ & $0.3125 \pm 2.56$ & $5.71 \pm 2.13$ & $705.65 \pm 0.524$ & $98.16 \pm 1.45$ \\
\hline F7 & $4.55 \pm 1.89$ & $0.4166 \pm 3.77$ & $4.0 \pm 1.45$ & $335.74 \pm 0.512$ & $96.66 \pm 3.55$ \\
\hline F8 & $4.21 \pm 1.65$ & $0.2666 \pm 4.65$ & $5.31 \pm 1.33$ & $697.41 \pm 0.716$ & $97.79 \pm 2.25$ \\
\hline F9 & $3.64 \pm 2.56$ & $0.3333 \pm 2.56$ & $5.11 \pm 2.02$ & $670.09 \pm 0.489$ & $96.56 \pm 4.45$ \\
\hline
\end{tabular}

